Received: September 6, 2000

\title{
Effective Method of Teaching Psychiatry to Undergraduate Medical Students: The Student Perspective
}

\author{
Abdullahi Fido Raghad Al-Kazemi \\ Department of Psychiatry, Faculty of Medicine, The Health Sciences Center, \\ Kuwait University, Kuwait
}

\section{Key Words}

Method of teaching psychiatry .

Undergraduate student perspectives

\begin{abstract}
Objectives: A search of the literature revealed that there are no studies of the effectiveness of teaching strategies from the medical students' perspective. This study aims to explore medical students' views on various teaching methods in psychiatry. Materials and Methods: A questionnaire describing several learning methods including clinical or bedside teaching, independent study, lectures, teaching aids, verbal/nonverbal behavior, and small-group teaching was administered to sixth-year medical students of the Faculty of Medicine, Health Sciences Center, Kuwait University. Results: Eighty-three percent of the students surveyed thought that well-delivered lectures were the most preferable learning method. Fifty-five percent
\end{abstract}

\begin{tabular}{ll}
\hline KARGER & ( 2001 S. Karger AG, Basel \\
Fax +41 61 306 1234 34 -7571/00/0094-0255 \$17.50/0 \\
$\begin{array}{l}\text { E-Mail karger@karger.ch } \\
\text { www.karger.com }\end{array}$ & $\begin{array}{l}\text { Accessible online at: } \\
\text { www.karger.com/journals/mpp }\end{array}$
\end{tabular}

agreed that live patient presentations were the most effective teaching aid. Independent study and small-group teaching were negatively viewed by $75 \%$ of the students. Slides/ overheads and video presentations were evaluated by students as the last useful teaching methods. Factors cited as helpful in teaching included an enthusiastic interactive lecturer, a clear, audible voice, and visual teaching materials. Conclusion: This finding suggests that medical students are able to differentiate between effective and ineffective teaching methods in psychiatry and because of this they remain among the keenest critics of the education they receive.

$$
\text { Copyright } \odot 2001 \text { S. Karger AG, Basel }
$$

\section{Introduction}

The lecture is the most traditional method of imparting knowledge to students. It is the teaching method that is used most frequently

\footnotetext{
Dr. Abdullahi Fido

Chairman, Department of Psychiatry, Faculty of Medicine

The Health Sciences Center, Kuwait University, PO Box 24923

Safat 13110 (Kuwait)

E-Mailfido@hsc.kuniv.edu.kw
} 
in the majority of medical schools desepite the problems that are often attributed to it [1]. Students attend countless hours of lectures, and they experience both exceptional and dull, uninteresting lectures. Poor lectures leave students feeling frustrated, wanting to give feedback to teachers [2]. Teaching aids such as slides, overheads, chalkboard presentations, and live patient presentations can make didactic lectures more effective if used properly [3]. It has been argued [4] that medical students develop a narrow perspective on learning and lack the knowledge and skills to keep abreast of the explosive growth of medical information and technology. There are many studies [5] on learning methods in the literature. Many of these studies, however, have taken place in the developed world where the language of instruction is the same as the student's first language. In Kuwait, the medical education system is largely based on the traditional British system. The undergraduate medical curriculum is comprised of 3 years of teaching in preclinical subjects followed by 3 years of clinical training based in teaching hospitals. While the Arabic language is the nation's native language, medical education is conducted in English. Evidence [6] suggests that medical students enter training with a negative attitude toward psychiatry. An optimistic view [7], however, indicates that the quality of psychiatric education in medical schools is an important determinant for the choice of a psychiatric career. The perspective of medical students regarding teaching methods in psychiatry has so far not been addressed. This article presents a unique study from the medical students' perspective, and its results are based on the perceptions of students rather than those of medical educators. The purpose of this study is to determine which strategies students perceive as effective for teaching psychiatry.
Table 1. Students' response to item questionnaire on various teaching methods

\section{Items}

Domain 1: Learning method

1 Clinical (bedside) teaching

2 Independent study

3 Small-group teaching

4 Lecture

5 Computer

\begin{aligned} & \hline \multicolumn{2}{c}{ Domain 2: Teaching aid } \\ & 6 Live patient presentation \\ & 7 Chalkboard \\ & 8 Slides \\ & 9 Video \\ & 10 Overheads \\ & 11 Computer-directed \end{aligned}

Domain 3: Verbal and nonverbal behavior

12 Enthusiasm

13 Language and voice (clear, audible and variable)

14 Eye contact with students

15 Movement and gestures

16 Sense of humor

Domain 4: Presentation component

17 Organized and logical lecturer

18 Comfortable and knowledgeable

19 Well paced

20 Material visible

21 Identification of important points and essential information emphasized

22 Summaries of key points

23 Linking ideas

24 Outline

\section{Methods}

A search was done of the medical education literature using the key words medical students, lectures, and students' perception from 1990 to 1999. Results revealed no studies from the medical student's perspective. After appraisal of the literature to facilitate content validity, a questionnaire was developed and divided into four domains: learning methods, teaching aids, lecture delivery, and presentation components. The survey was limited to 24 items as shown in table 1 . The initial questionnaire was pilot-tested on 5 sixthyear medical students. Their critical appraisal resulted in revision for clarity and reliability. The question- 
Fig. 1. Responses of medical students to various learning methods.

Fig. 2. Responses of medical students to various teaching aids.
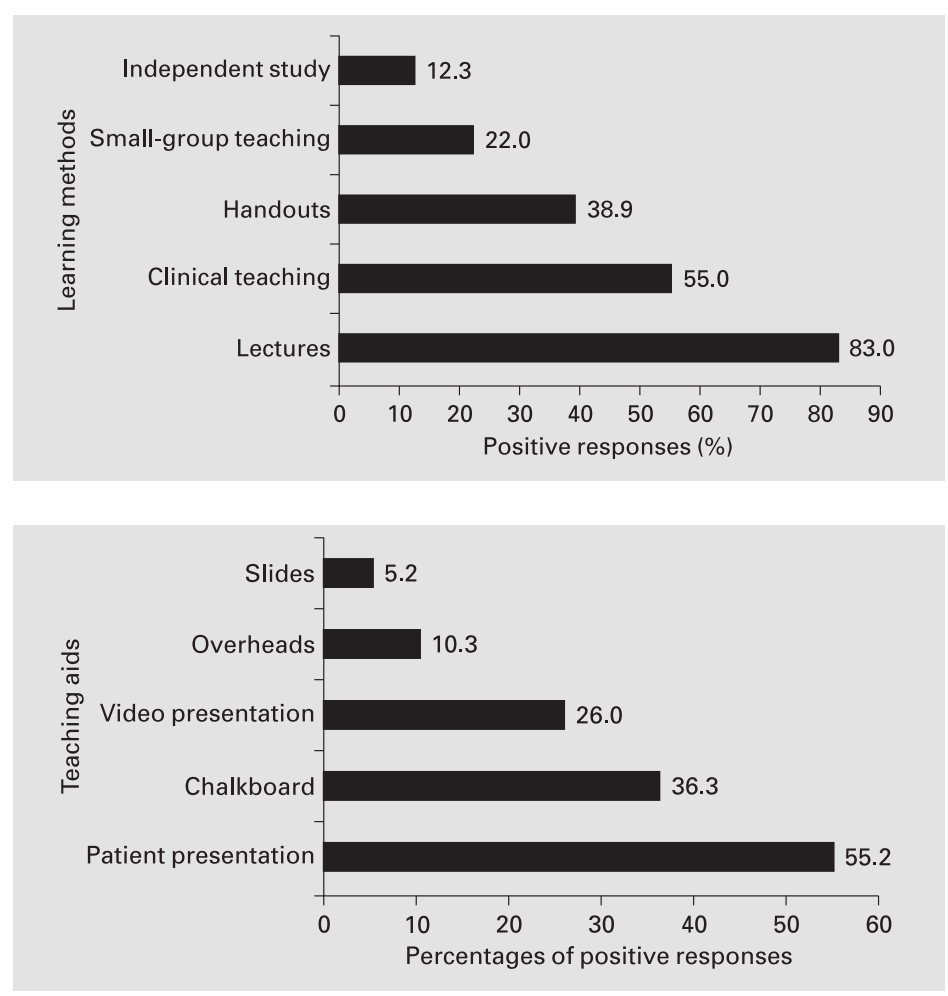

naire was administered anonymously to two consecutive classes of sixth-year medical student $(n=92)$ receiving psychiatric training at the Faculty of Medicine, Health Sciences Center, Kuwait University. The sixth-year psychiatric curriculum comprises $5 \mathrm{~h}$ of didactic lectures per week, 6 weeks of communication skills, phenomenology, diagnostic classification, etiology, clinical features, and treatment of psychiatric disorders. In addition, the students were divided into groups of 5-6 students and spent another 5 days per week rotating in acute, chronic, substance abuse, forensic and outpatient clinics. The content of this second program was mostly practical, including case presentations, student group discussions, one-way mirror observations, video recordings of interview techniques and various treatment intervention modalities. The program required active student participation. Seven academic psychiatrics were involved in the training program. Except when interviewing native Arabicspeaking patients, all discussions and teaching materials were conducted in the English language. The quality of each teaching method was rated on a nominal scale of helpful or unhelpful. Confidentiality was en- sured at all times. The questionnaire was given at the end of a 6-week rotation period. Summary descriptive statistics were used and figures were developed to display results.

\section{Results}

All 92 students returned the questionnaire, 60 female and 32 male participants with a mean age of 23.5 years. The majority of the students $(83 \%)$ thought that well-delivered lectures were the most effective learning method; independent study and small-group teaching were negatively viewed (fig. 1). Fiftyfive percent $(55 \%)$ of the students agreed that live patient presentations were the most effective teaching aid while slides/overheads and video presentations were evaluated by the students as not being helpful (fig. 2). Verbal and 
Fig. 3. Endorsements of medical students to various verbal and nonverbal behavior.

Fig. 4. Endorsements of medical students to teaching characteristics of the lecturer.
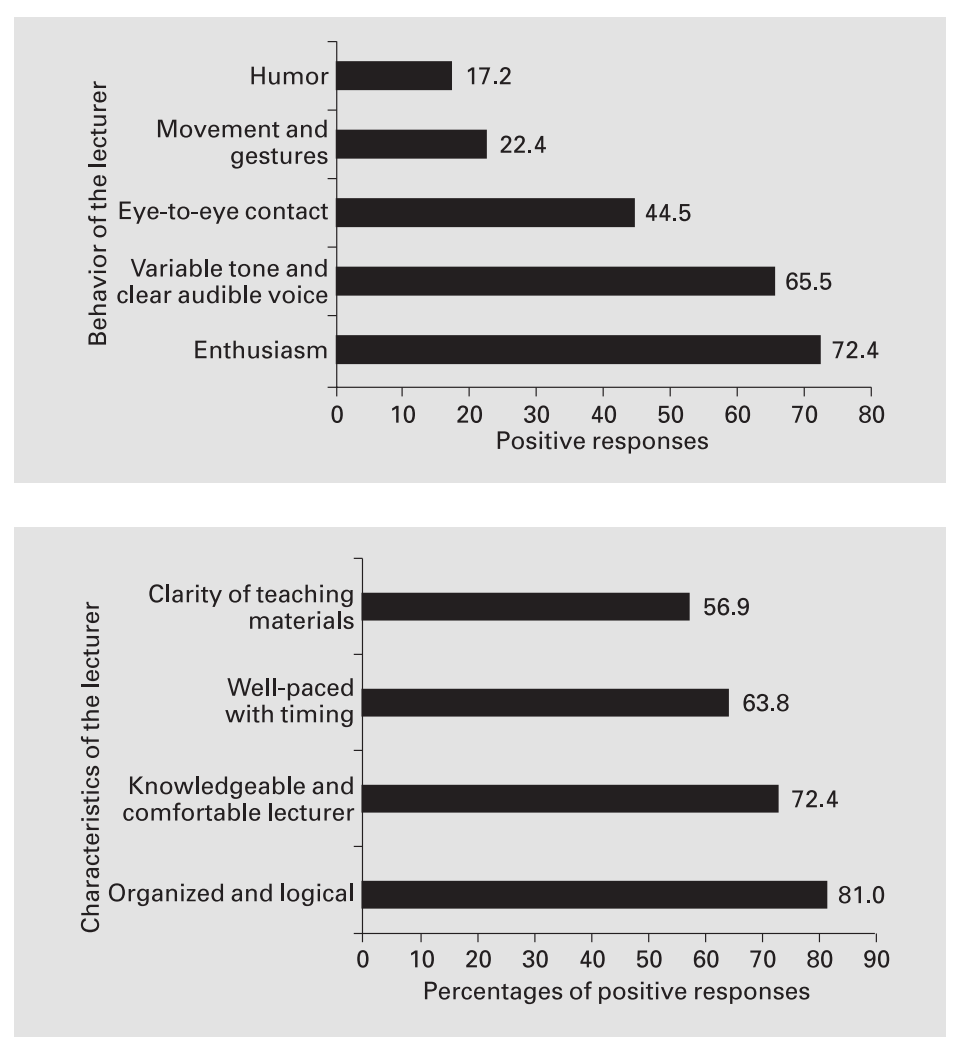

nonverbal behavior considered most useful in teaching included an enthusiastic, interactive lecturer with a clear audible voice and visual teaching materials (fig. 3). All the teaching characteristics of the lecturer evaluated were considered helpful with organized, logical lectures being the most important (fig. 4). There was no significant difference between male and female student responses.

\section{Discussion}

This study was undertaken to ascertain the perception of a group of senior medical students undergoing a psychiatric clerkship. The impressive $100 \%$ response rate to our questionnaire testifies to the students' interest and concern. This survey revealed that most Faculty of Medicine, Health Sciences Center, Kuwait University sixth-year medical students attended and enjoyed interesting lectures. Unlike slides/overhead and video presentations, a significant number of students, $83 \%$, found that lectures that were well delivered were the most effective learning method. This result is consistent with Butler's [8] report on problems associated with teaching methods that lie less with the method itself but rather with its ineffective use. More than one half of the students considered the live patient presentation format to be an effective teaching aid because it promoted the students' direct participation and allowed patients the opportunity to share their experience. Interestingly, the traditional chalkboard 
presentation teaching method was still regarded as useful by a minority of students, an attitude which is probably related to the traditional teacher-centered pedagogy used throughout the school system in Kuwait. Unlike an earlier report [9], a great majority of students thought that independent study and small-group teaching were the least useful teaching methods. Factors cited as helpful in teaching included an enthusiastic interactive lecturer, a clear audible voice, visual teaching materials and the judicious use of humor. An earlier assertion [10] that lectures as a method of teaching induce in students a 'passive reproductive mental set' has not been substantiated by this survey. On the contrary, this survey has shown that students want to be actively involved in learning despite the anecdotal notion that they prefer to be 'spoonfed'.
This study has some obvious limitations. Only one medical school was surveyed and only one class participated. Logistics and funding precluded our ability to survey other student bodies elsewhere. However, we felt that the sixth-year students of the Faculty of Medicine, Health Sciences Center, Kuwait University were best able to assess effective teaching methods in psychiatric in our institution.

\section{Conclusion}

The findings suggest that the preference of medical students may be related to the effectiveness of the method of teaching. Future studies should employ objective measures such as the change in knowledge level to provide more qualitative and quantitative analyses.

\section{References}

1 Nemble D, Camron R: Helping Students Learn: A Handbook for Medical Teachers, ed 3. Boston, Kluwer Academic Publishers, 1994, pp 165-191.

2 Laidlow T: Twelve types of lectures. Med Teach 1988;10:13-17.

3 Gibbs G, Hobeshar T: Improving students' learning during lectures. Med Teach 1987;9:11-20.

4 Taylor G: Improving medical education. Acad Med 1994;69:631634.
5 ACME: Educating medical students: Assessing change in medical education: The road to implementation. Acad Med 1993;68(suppl).

6 Fido A: Medical students' attitude to psychiatry. Med Principles Pract 1996:3:70-74.

7 Lee E, Kaltreider N, Crouch J: Pilot study of current factors influencing the choice of psychiatry as a specialty. Am J Psychiatry 1995;152:10661069 .
8 Butler J: Use of teaching methods within the lecture format. Med Teach 1992;14:11-25.

9 Schwartz P: Active, small group teaching in a large group: A practical example. Med Teach 1989;11:8186.

10 Metcalf D, Matharu M: Students' perception of good and bad teaching: Reports of a critical incident study. Med Educ 1995;29:193-197. 